\title{
QUALIDADE DA MADEIRA SERRADA DE Pinus elliottii ENGELM. PROCEDENTE DE FLORESTAS RESINADAS
}

\author{
Pedro Henrique Gonzalez de Cademartori', Darci Alberto Gatto ${ }^{2}$, Diego Martins Stangerlin ${ }^{3}$, \\ Eduardo Schneid ${ }^{4}$, Leandro Gonçalves Hamm ${ }^{4}$
}

(recebido: 11 de outubro de 2010; aceito: 28 de abril de 2012)

\begin{abstract}
RESUMO: Neste estudo, objetivou-se caracterizar a qualidade da madeira serrada de Pinus elliottii procedente de florestas resinadas e processadas em uma serraria instalada no município de São José do Norte (RS). Para tanto, selecionaram-se, do processamento de desdobro, quatro toras basais e quatro toras superiores para cada uma das três classes diamétricas existentes. As peças originadas foram analisadas pós-desdobro e pós-secagem em estufa convencional convectiva. Constatou-se, em razão da inexistência de tratos silviculturais na floresta, a incidência de nós, principalmente nas peças de toras superiores, influenciando a classificação qualitativa dessas peças de madeira. Em relação à operação de resinagem, esta contribuiu para a maior incidência de bolsas de resina nas peças de toras basais, além de que, influenciou na classificação qualitativa da madeira. O surgimento de defeitos após a operação de secagem não alterou a classificação da madeira tanto oriunda de toras basais como de toras superiores.
\end{abstract}

Palavras-chave: Resinagem da madeira, tecnologia da madeira, defeitos da madeira, secagem em estufa, desdobro.

\section{QUALITY OF Pinus elliottii SAWN TIMBER FROM TAPPED FORESTS}

\begin{abstract}
This study aimed to characterize the quality of Pinus elliottii sawn timber extracted from tapped forests and processed in a sawmill in São José do Norte (RS). Four butt logs and four upper logs for each of the three existing diameter grades were selected and sawed. The wood pieces were analyzed after sawing and after kiln drying. The presence of knots, which occurred due to the absence of forest management and influenced the qualitative classification of the wood pieces, was observed mainly in the samples from upper logs. The process of resin tapping contributed to a higher incidence of resin pockets in the samples from butt logs, also influencing the qualitative classification of the samples. The appearance of drying defects did not modify the classification of the wood samples from butt and upper logs.
\end{abstract}

Key words: Wood resin tapping, wood technology, wood flaws, kiln drying, sawing.

\section{INTRODUÇÃO}

O decréscimo mundial de florestas nativas ao redor do mundo e a necessidade de madeira como matéria-prima, tanto em escala industrial como comercial, alavancou as atividades de florestamento e reflorestamento. Dessa forma, o Pinus tornou-se um dos gêneros mais requisitados para a realização de plantios manejados e de rápido crescimento no Brasil, tal como o eucalipto. Das espécies de Pinus plantadas no Brasil, destaca-se Pinus elliottii Engelm., por apresentar viabilidade na produção de resinas, madeira serrada em geral, madeira roliça (postes e moirões), polpa e papel, e painéis laminados e particulados.
Salienta-se a relevância do processo de resinagem realizado nas árvores do gênero Pinus pela sua abrangência em termos de mercado consumidor e escala industrial, já que é considerado como uma forma secundária e rentável de aproveitamento da floresta plantada. No entanto, a resinagem pode influenciar diretamente em diversos aspectos qualitativos da madeira, tais como: propriedades físicas, mecânicas e organolépticas. Dessa forma, o conhecimento da qualidade da madeira da espécie Pinus elliottii é indispensável para que produtos oriundos desse material possam ganhar mercado e estabelecer um conceito cada vez mais favorável entre os consumidores.

${ }^{1}$ Graduado em Engenharia Industrial Madeireira, Mestrando em Ciência e Engenharia de Materiais - Universidade Federal de Pelotas/UFPel - Rua Félix da Cunha, 809 - 96010-000 - Pelotas, RS, Brasil - pedrocademartori@gmail.com

${ }^{2}$ Engenheiro Florestal, Professor Doutor em Engenharia Florestal - Universidade Federal de Pelotas/UFPel - Centro de Engenharias Engenharia Industrial Madeireira - Rua Conde de Porto Alegre, 793 - 96010-290 - Pelotas, RS, Brasil - darcigatto@yahoo.com ${ }^{3}$ Engenheiro Florestal, Professor Doutor em Ciências Florestais - Universidade Federal de Mato Grosso/UFMT - Instituto de Ciências Agrárias e Ambientais - Avenida Alexandre Ferronato, 1200 - 78550-000 - Sinop, MT, Brasil - diego_stangerlin@yahoo.com.br ${ }^{4}$ Graduado em Engenharia Industrial Madeireira, Mestrando em Engenharia Florestal - Universidade Federal de Santa Maria/UFSM Programa de Pós-Graduação de Engenharia Florestal - Avenida Roraima, 1000 - Bairro Camobi - 97105-900 - Santa Maria, RS, Brasil eduardoschneid87@gmail.com, leandrohamm@hotmail.com 
Todavia, para um processamento ideal das toras, é necessário considerar uma série de fatores, tais como: a qualidade do maquinário, a qualidade da matéria-prima (toras de madeira), a mão de obra, além da escolha adequada das técnicas de desdobro de acordo com a produção requerida. Ainda assim, Hochheim e Martin (1993) afirmaram que a qualidade das toras influencia no processo produtivo de uma serraria, visto que todas as decisões de corte são tomadas em razão da qualidade visual, com consequência sobre o rendimento e a velocidade do fluxo dos produtos de elaboração.

Além disso, a realização de uma operação de secagem correta viabiliza a obtenção de madeira seca com a qualidade comercial desejada. Segundo Jankowsky (1992), a qualidade da madeira seca depende, inicialmente, da preparação da carga (classificação da matéria-prima e empilhamento) e, finalmente, do controle de qualidade do produto final (madeira seca). Entretanto, a remoção da água do interior da madeira acompanhada pelo desenvolvimento de tensões resultantes da diferença de umidade entre regiões contíguas e da anisotropia de contração resultará no aparecimento de defeitos na madeira, tais como: empenamentos e rachaduras (SANTINI, 1992). Com isso, o conhecimento das características intrínsecas da madeira e das técnicas de secagem permite exercer um controle mais efetivo sobre a operação.

As consequências de incorretos processos de manejo florestal, desdobro e secagem são reconhecidas a partir da incidência de defeitos na madeira serrada. Estes são definidos como todas as anomalias da forma do tronco da árvore, da sua seção transversal, como também da estrutura e da cor do lenho que possam reduzir, restringir ou mesmo anular a utilização da madeira (GROSSER, 1980).

Dessa forma, no presente trabalho, objetivou-se caracterizar a qualidade da madeira serrada de Pinus elliottii de toras basais e toras superiores procedentes de florestas resinadas.

\section{MATERIAL E MÉTODOS}

\subsection{Caracterização da área de estudo}

Desenvolveu-se o estudo em uma serraria instalada no município de São José do Norte, região Sul do Estado do Rio Grande do Sul. Tal serraria caracteriza-se por ser a única da região Sul do Rio Grande do Sul a produzir madeira serrada procedente de florestas resinadas (10 a 12 vezes antes do corte), com idade entre 28 e 32 anos e não manejadas.

\subsection{Caracterização do material de estudo}

Para a seleção das toras para desdobro, adotou-se uma divisão em três classes diamétricas $(15-20 \mathrm{~cm} ; 21-25$ $\mathrm{cm}$ e $26-30 \mathrm{~cm}$ ), levando em conta a disponibilidade de toras na serraria. Para cada classe diamétrica, foram selecionadas, por amostragem aleatória simples, quatro toras basais (primeira tora retirada a partir da base da árvore e com a presença de estrias de resinagem) e quatro toras superiores (quaisquer toras localizadas acima da tora basal), totalizando oito toras por classe diamétrica e, consequentemente, 24 toras de madeira de Pinus elliottii procedentes de florestas localizadas na região litorânea de São José do Norte.

As toras foram transportadas da floresta para a serraria com comprimento entre $1,90 \mathrm{~m}$ e 2,10 m e diâmetro a partir de $15 \mathrm{~cm}$. Foram depositadas no pátio de toras ao ar livre e em contato direto com o solo. Após o descascamento, ocorreu o corte principal para a formação de blocos a partir da tora de madeira por meio de uma serra fita dupla. A etapa seguinte consistiu na destopagem do bloco por meio de uma destopadeira. A linha principal de desdobro finalizou-se com a formação das tábuas com o uso de uma serra fita horizontal de seis cabeçotes.

\subsection{Avaliação dos defeitos de desdobro}

Analisou-se a qualidade das peças produzidas quanto à variação da espessura ao longo do comprimento. Para tal verificação, definiram-se de três a quatro pontos de medição da espessura das peças, a partir do comprimento final da peça. Em cada ponto, efetuaram-se duas medições nas laterais das peças para a identificação de irregularidades durante o desdobro ou após a secagem. Permitiu-se uma variação da espessura nominal de $3 \mathrm{~mm}$ para peças que apresentaram espessura entre 12 e $25 \mathrm{~mm}$ em, no máximo, 25\% do lote, conforme a Associação Brasileira de Normas Técnicas - ABNT (1991c).

\subsection{Avaliação dos defeitos naturais e de secagem}

A avaliação qualitativa e quantitativa dos defeitos naturais (nó, bolsa de resina, medula, esmoado, mancha azul, furo de inseto e rachadura) e de secagem (empenamentos) nas peças desdobradas foi realizada conforme os procedimentos da ABNT (1991b), levando em conta as classes diamétricas pré-definidas. Para cada tora desdobrada, selecionaram-se duas peças de madeira pelo método de amostragem aleatória simples, totalizando 48 peças de madeira ( 24 peças oriundas da tora basal e 24 peças oriundas da tora superior). Com a madeira em estado

Cerne, Lavras, v. 18, n. 4, p. 577-583, out./dez. 2012 
verde (pós-desdobro), foram analisados apenas os defeitos naturais. Já, com a madeira seca (pós-secagem), além dos defeitos naturais, foram quantificados os defeitos resultantes da secagem.

A verificação dos defeitos naturais e de secagem presentes nas peças permitiu classificá-las em classes de qualidade (extra, super, primeira, segunda ou terceira) de acordo com os procedimentos da ABNT (1991a).

\section{RESULTADOS E DISCUSSÃO}

\subsection{Defeitos de desdobro}

Observa-se, na Tabela 1, que ambos os tratamentos apresentam uma diferença estatística significativa a um nível de 5\% de probabilidade de erro entre peças verdes e secas, para uma bitola de $16 \mathrm{~mm}$ (tora basal) e $23 \mathrm{~mm}$ (tora superior). Igualmente, tanto as peças da tora basal como da tora superior não excederam os limites propostos pela
ABNT (1991c) quanto à variação da espessura nominal nos estados verde e seco.

\subsection{Defeitos naturais}

Demonstra-se, por meio da Tabela 2, que o número de nós $/ \mathrm{m}^{2}$ médio em ambos os tratamentos antes e depois da secagem não apresentaram diferença estatística significativa a um nível de $5 \%$ de probabilidade de erro, caracterizando-se como grupos homogêneos. $\mathrm{O}$ aumento do número de nós $/ \mathrm{m}^{2}$ deve-se, principalmente, ao fato de a área superficial da peça ter diminuído após a operação de secagem em estufa convectiva, já que ocorreu a contração da madeira com a saída da água presente em seu interior.

Na Tabela 3, constata-se que ambos os tratamentos (tora basal e tora superior) não diferem estatisticamente a um nível de $5 \%$ de probabilidade de erro em relação a proporção de nós.

Tabela 1 - Variação da espessura das peças de madeira oriundas da tora basal e tora superior de Pinus elliottii.

Table 1 - Thickness variation of Pinus elliottii wood pieces from butt and upper logs.

\begin{tabular}{lccccc}
\hline \multirow{2}{*}{ Dados } & \multicolumn{2}{c}{ Tora basal } & \multicolumn{2}{c}{ Tora superior } \\
\cline { 2 - 6 } & Verde & Seca & Verde & Seca \\
\hline Mínimo (mm) & 14,64 & 14,44 & 20,94 & 14,23 \\
Máximo (mm) & 19,53 & 18,87 & 26,43 & 27,74 \\
Média (mm) & $16,76^{\mathrm{a}}$ & $16,23^{\mathrm{b}}$ & $23,84^{\mathrm{a}}$ & $23,03^{\mathrm{b}}$ \\
DP & 0,68 & 0,74 & 0,95 & 1,09 \\
CV $(\%)$ & 4,09 & 4,57 & 2,83 & 2,51 \\
\hline F & & & 58,52 & $<0,001$ \\
p & 37,24 & & & $<0,001$ \\
\hline
\end{tabular}

Em que: DP = Desvio Padrão; CV = Coeficiente de Variação; F = Valor de F calculado; $\mathrm{p}=$ Probabilidade de erro; Médias seguidas da mesma letra não diferem estatisticamente a um nível de 5\% de probabilidade de erro pelo teste de Fisher (LSD).

Tabela 2 - Valores do número de nós por metro quadrado (nós $/ \mathrm{m}^{2}$ ) para peças de madeira oriundas da tora basal e da tora superior.

Table 2 - Number of knots per square meter $\left(k n o t s / m^{2}\right)$ of wood pieces from butt and upper logs.

\begin{tabular}{lccccc}
\hline \multirow{2}{*}{ Dados } & \multicolumn{3}{c}{ Tora basal } & \multicolumn{2}{c}{ Tora superior } \\
\cline { 2 - 6 } & Verde & & Seca & Verde & Seca \\
\hline Mínimo & 3,70 & 3,80 & 7,70 & 35,50 \\
Máximo & 40,60 & 42 & 34,70 & $21,08^{\mathrm{a}}$ \\
Médio & $22,63^{\mathrm{a}}$ & & $23,38^{\mathrm{a}}$ & $20,32^{\mathrm{a}}$ & 8,10 \\
DP & 8,76 & & 9,08 & 8,03 & 0,10 \\
\hline F & & 0,08 & & & 0,75 \\
P & 0,77 & & & \\
\hline
\end{tabular}

Em que: DP = Desvio Padrão; F = Valor de F calculado; $\mathrm{p}$ = Probabilidade de erro; Médias seguidas da mesma letra não diferem estatisticamente a um nível de 5\% de probabilidade de erro pelo teste de Fisher (LSD). 
Tabela 3 - Proporção de nós para peças de madeira oriundas da tora basal e da tora superior.

Table 3 - Proportion of knots of wood pieces from butt and upper logs.

\begin{tabular}{|c|c|c|c|c|}
\hline \multirow{2}{*}{ Dados } & \multicolumn{2}{|c|}{ Tora basal } & \multicolumn{2}{|c|}{ Tora superior } \\
\hline & Verde & Seca & Verde & Seca \\
\hline Mínimo (\%) & 11 & 12 & 15 & 16 \\
\hline Máximo (\%) & 77 & 80 & 156 & 158 \\
\hline Médio (\%) & $47^{\mathrm{a}}$ & $48^{\mathrm{a}}$ & $75^{\mathrm{a}}$ & $78^{\mathrm{a}}$ \\
\hline DP & 18,07 & 18,59 & 40,23 & 40,92 \\
\hline $\mathrm{F}$ & \multicolumn{2}{|c|}{0,08} & \multicolumn{2}{|c|}{0,09} \\
\hline $\mathrm{P}$ & \multicolumn{2}{|c|}{0,78} & \multicolumn{2}{|c|}{0,77} \\
\hline
\end{tabular}

Em que: $\mathrm{DP}=$ Desvio Padrão; F = Valor de F calculado; $\mathrm{p}=$ Probabilidade de erro; Médias seguidas da mesma letra não diferem estatisticamente a um nível de 5\% de probabilidade de erro pelo teste de Fisher (LSD).

As peças oriundas da tora superior apresentaram valores de proporção de nós significativamente superiores quando comparados com as peças oriundas da tora basal, pelo fato de a floresta responsável por abastecer a serraria não sofrer nenhum tipo de manejo silvicultural, especificamente a desrama. Larson et al. (2001) afirmaram que a quantidade de nós aumenta significativamente com a altura do tronco na direção da copa da árvore. Para tal, segundo Schneider et al. (1999), a desrama objetiva a melhoria das propriedades físicas da madeira serrada a partir da redução da quantidade e tamanho de nós e também por meio da eliminação de nós mortos ou soltos. Qualitativamente, um dos pontos afetados pela presença de nós é a resistência da madeira. Ainda assim, Kretschmann (2010) afirmou que os efeitos sobre a resistência da madeira dependem da proporção ocupada pelo nó na tábua e localização do nó, além da distribuição de esforços na peça.

Por meio da Tabela 4, pode-se afirmar que a elevada presença de nós cariados em ambos os tratamentos ocorreu pela inexistência de trato silvicultural na floresta e a consequente quebra natural dos galhos, aliado ao processo de deterioração por fungos e insetos.

Já, na Tabela 5, observa-se uma elevada incidência de bolsas de resina nas peças oriundas de toras basais $(62,50 \%)$ quando comparadas às peças oriundas de toras superiores $(29,17 \%)$.

A elevada incidência de bolsas de resina nas peças originárias das toras basais deve-se ao fato de que as mesmas sofreram diretamente a operação de resinagem, implicando em uma maior quantidade de resina presente, especificamente, na parcela da árvore correspondente à tora
Tabela 4 - Tipos de nós observados nas peças de madeira originárias da tora basal e tora superior.

Table 4 - Type of knots observed in wood pieces from butt and upper logs.

\begin{tabular}{lcc}
\hline \multirow{2}{*}{ Tipo de nó } & \multicolumn{2}{c}{ Quantidade $(\%)$} \\
\cline { 2 - 3 } & Tora basal & Tora superior \\
\hline Gravata & 6,80 & 11,12 \\
Cariado & 36,73 & 34,13 \\
Firme & 50,34 & 41,27 \\
Quina & 6,12 & 10,31 \\
Solto & 0 & 3,17 \\
\hline
\end{tabular}

basal. Além disso, o fato de a operação de resinagem repetirse de 10 a 12 vezes antes do abate da árvore também contribuiu para a formação de bolsas de resina, a partir do fechamento da estria, durante a operação de resinagem e a ineficiência operacional, ou seja, incorreta aplicação do ácido.

$\mathrm{O}$ esmoado foi identificado em apenas duas peças de cada tratamento. Já, a presença de medula incidiu em $45,83 \%$ das peças originárias de toras basais, valor superior ao encontrado nas peças oriundas de tora superiores $(29,17 \%)$. Supõe-se que os resultados obtidos devem-se à casualização das peças, possivelmente, oriundas da região central da tora, visto que Antonelli et al. (2008) afirmaram que a resinagem não determina a presença de diferenças significativas em relação ao deslocamento da medula para toras basais e toras superiores oriundas de árvores resinadas de Pinus elliottii var. elliottii e Pinus caribaea var. hondurensis. Não foram identificadas manchas do tipo azul e marrom nas peças. Segundo Veiga (1983), é comum

Cerne, Lavras, v. 18, n. 4, p. 577-583, out./dez. 2012 
Tabela 5 - Análise qualitativa dos defeitos naturais da madeira serrada de Pinus elliottii.

Table 5 - Qualitative analysis of natural flaws of Pinus elliottii sawn timber.

\begin{tabular}{lccc}
\hline \multirow{2}{*}{ Defeitos naturais } & Amostras com defeito & \multicolumn{2}{c}{ Origem } \\
\cline { 2 - 3 } Bolsa de resina & $\mathrm{N}^{\circ}$ de peças & Tora basal & Tora superior \\
\hline \multirow{2}{*}{ Esmoado } & $(\%)$ & 15 & 7 \\
& $\mathrm{~N}^{\circ}$ de peças & 62,50 & 29,17 \\
\hline \multirow{2}{*}{ Medula } & $(\%)$ & 2 & 2 \\
& $\mathrm{~N}^{\circ}$ de peças & 8,33 & 7 \\
Mancha azul & $(\%)$ & 11 & 29,17 \\
\hline \multirow{2}{*}{ Mancha marrom } & $\mathrm{N}^{\circ}$ de peças & 45,83 & 0 \\
\hline \multirow{2}{*}{ Rachaduras de topo } & $(\%)$ & 0 & 0 \\
\hline \multirow{2}{*}{ Furos de insetos inativos } & $\mathrm{N}^{\circ}$ de peças & 0 & 0 \\
\hline
\end{tabular}

encontrar manchas azuis em toras empilhadas nos carreadores em torno dos talhões. Dessa forma, identificase um sistema de manuseio e transporte das toras adequado entre a floresta e a serraria, visto que as árvores são abatidas e, em tempo hábil, as toras são transportadas para o pátio da serraria para posterior processamento.

Já, as manchas marrons não foram identificadas, em razão da inexistência de processo de aplainamento e lixamento das peças de madeira após o processo de desdobro e secagem, visto que esses processos permitem a identificação do ataque dos fungos. Conforme Millett (1952), a ocorrência de mancha marrom é influenciada por fatores como intervalos de tempo entre o abate da árvore e o desdobro e entre o desdobro e a secagem, condições de secagem, além da presença de extrativos. O autor ainda afirmou que a mancha marrom ocorre mais intensamente na secagem artificial (em altas temperaturas) do que ao ar livre.

Mesmo assim, não se pode confirmar a eficácia da operação de secagem em estufa convectiva, bem como o sistema de logística e transporte floresta-serraria, em razão da não realização dos processos de lixamento e aplainamento, mencionados anteriormente.

Não se identificou a presença de rachaduras de topo ao longo do comprimento das peças, visto que esse tipo de defeito ocorre em decorrência da secagem muito rápida das extremidades das peças e também pela ação das tensões de crescimento, essencialmente presente na madeira do gênero Eucalyptus. Além disso, não se verificaram furos de insetos inativos na madeira.

\subsection{Defeitos de secagem}

Observa-se, na Tabela 6, que apenas o arqueamento médio entre as peças da tora basal $(0,33 \%)$ e da tora superior $(0,16 \%)$ diferiu estatisticamente a um nível de $5 \%$ de probabilidade de erro.

Cientificamente, não se encontrou nenhum estudo que comprovasse a influência da resinagem na elevação da ocorrência de defeitos de secagem nas toras estriadas. Entretanto, a significativa variação entre os valores máximos obtidos na ocorrência de arqueamento entre a tora basal e a tora superior justifica a existência de uma mínima influência. De acordo com Baena (1994), a resinagem consiste em fazer cortes em estrias nas aberturas naturais do lenho para que a resina, que se encontra sob pressão, exsude. Dessa forma, afirma-se que a resina tende a concentrar-se ao entorno das estrias pela estimulação dos ácidos introduzidos na árvore.

Aliado a esse fato, é relevante citar que a magnitude da retratibilidade longitudinal depende do tipo de madeira, massa específica, bem como da existência e quantidade de extrativos. Além disso, determinadas substâncias, tais como

Cerne, Lavras, v. 18, n. 4, p. 577-583, out./dez. 2012 
Tabela 6 - Análise dos empenamentos verificados nas tábuas oriundas de toras basais e superiores.

Table 6 - Analysis of warps in boards from butt and upper logs.

\begin{tabular}{|c|c|c|c|c|c|c|c|}
\hline & Tábuas & DP & Mín. (\%) & Máx. (\%) & Médio (\%) & $\mathrm{F}$ & $\mathrm{p}$ \\
\hline \multirow{2}{*}{ Encurvamento } & Basal & 0,19 & 0,0 & 0,6 & $0,15^{\mathrm{a}}$ & \multirow{2}{*}{0,01} & \multirow{2}{*}{0,94} \\
\hline & Superior & 0,20 & 0,0 & 0,7 & $0,16^{\mathrm{a}}$ & & \\
\hline \multirow{2}{*}{ Arqueamento } & Basal & 0,31 & 0,0 & 1,58 & $0,33^{\mathrm{a}}$ & \multirow{2}{*}{5,24} & \multirow{2}{*}{0,03} \\
\hline & Superior & 0,13 & 0,0 & 0,55 & $0,16^{\mathrm{b}}$ & & \\
\hline \multirow{2}{*}{ Encanoamento } & Basal & 0,03 & 0,0 & 0,11 & $0,02^{\mathrm{a}}$ & \multirow{2}{*}{1,18} & \multirow{2}{*}{0,28} \\
\hline & Superior & 0,03 & 0,0 & 0,10 & $0,01^{\mathrm{a}}$ & & \\
\hline
\end{tabular}

Em que: DP = Desvio Padrão; F = Valor de F calculado; $\mathrm{p}=$ Probabilidade de erro; Médias seguidas da mesma letra não diferem estatisticamente a um nível de 5\% de probabilidade de erro pelo teste de Fisher (LSD).

resinas, taninos, óleos e produtos introduzidos artificialmente, podem modificar a retratibilidade de madeira (DURLO; MARCHIORI, 1992). Com isso, teoricamente, explica-se o fato de a tora basal, em comparação a tora superior ter apresentado maiores valores médios de intensidade de arqueamento após a secagem em estufa convectiva.

\subsection{Classificação quanto à qualidade}

Observa-se, na Tabela 7, que, para peças oriundas de toras basais, ocorreu a dominância da classe Terceira, tanto no estado verde como no seco. Explica-se tal superioridade a partir do grande número de bolsas de resina encontradas nas amostras, visto que a circulação de resina na tora basal é maior pelo estímulo do processo de resinagem. Já para peças oriundas de toras superiores, nota-se a dominância da classe Segunda em ambos os estados, verde e seco. Nesse caso, a principal interferência na classificação das peças foi a quantidade e o tamanho dos nós.

Tabela 7 - Classes de qualidade para peças de madeira verde e seca oriundas da tora basal e da tora superior.

Table 7 - Quality grades of green pieces and dry pieces of wood from butt and upper logs.

\begin{tabular}{lcccc}
\hline \multirow{2}{*}{ Classe } & \multicolumn{2}{c}{$\begin{array}{c}\text { Peças - Tora Basal } \\
(\%)\end{array}$} & \multicolumn{2}{c}{$\begin{array}{c}\text { Peças - Tora Superior } \\
(\%)\end{array}$} \\
\cline { 2 - 5 } & Verde & Seca & Verde & Seca \\
\hline Extra & 0 & 0 & 0 & 0 \\
Super & 0 & 0 & 0 & 0 \\
Primeira & 29 & 29 & 21 & 21 \\
Segunda & 33 & 33 & 62 & 62 \\
Terceira & 38 & 38 & 17 & 17 \\
\hline
\end{tabular}

Tanto nas peças de toras basais como de toras superiores, os empenamentos identificados foram ínfimos a ponto de não interferirem na qualidade da madeira e, conseguintemente, alterar sua classificação.

\section{CONCLUSÕES}

A operação de desdobro não influenciou na produção de madeira serrada com defeitos, resultando em peças homogêneas, de acordo com a normalização vigente.

A elevada incidência de nós nas peças de madeira, principalmente oriundas da tora superior ocorreu, em razão da inexistência de tratos silviculturais na floresta responsável por abastecer a serraria;

A operação de resinagem contribuiu substancialmente para a elevação da quantidade de bolsas de resina nas peças de madeira da tora basal;

A operação de resinagem influenciou a ocorrência predominante da classe Terceira nas peças de madeira oriundas da tora basal, estas apresentando qualidade inferior às peças de madeira oriundas da tora superior.

O surgimento de defeitos, após a operação de secagem, não alterou a classificação da madeira.

Dessa forma, recomenda-se a implantação de um plano de manejo florestal com o intuito de diminuir a incidência de nós nas peças de madeira.

\section{REFERÊNCIAS}

ANTONELLI, P. O.; ANTUNES JÚNIOR, R. O.; GARCIA, J. N. Influência da resinagem no deslocamento de medula do Pinus elliottii var elliottii e Pinus caribaea var hondurensis. In: SIICUSP, 16., 2008, São Paulo. Anais... São Paulo: USP, 2008. 1 CD-ROM.

Cerne, Lavras, v. 18, n. 4, p. 577-583, out./dez. 2012 
ASSOCIAÇÃO BRASILEIRA DE NORMAS TÉCNICAS. NBR 11700: madeira serrada de coníferas provenientes de reflorestamento para uso geral: classificação. Rio de Janeiro, 1991a. 6 p.

ASSOCIAÇÃO BRASILEIRA DE NORMAS TÉCNICAS. NBR 12297: madeira serrada de coníferas provenientes de reflorestamento, para uso geral: medição e quantificação de defeitos. Rio de Janeiro, 1991b. 6 p.

ASSOCIAÇÃO BRASILEIRA DE NORMAS TÉCNICAS. NBR 12498: madeira serrada de coníferas provenientes de reflorestamento, para uso geral: dimensões e lotes: padronização. Rio de Janeiro, 1991c. 5 p.

BAENA, E. de S. Análise da viabilidade econômica da resinagem em Pinus elliottii Engelm. var elliottii nas regiões Sul do Estado do Paraná e Sul e Sudoeste do Estado de São Paulo. 1994. 94 f. Tese (Doutorado em Ciências Florestais) - Universidade Federal do Paraná, Curitiba, 1994.

DURLO, M. A.; MARCHIORI, J. N. C. Tecnologia da madeira: retratibilidade. Santa Maria: CEPEF/FATEC, 1992. 33 p. (Série técnica, 10).

GROSSER, D. Defeitos da madeira. Curitiba: FUPEF, 1980. 63 p. (Série técnica, 2).

HOCHHEIM, N.; MARTIN, P. Influência da qualidade das toras no processo de fabricação, rendimento, custo e rentabilidade da madeira serrada. In: CONGRESSO FLORESTAL PAN-AMERICANO, 1.; CONGRESSO FLORESTAL BRASILEIRO, 7., 1993, Curitiba. Anais... Curitiba: SBS-SBEF, 1993. p. 644-646.
JANKOWSKY, I. P. O controle do processo de secagem. In: SIMPÓSIO FLORESTAL DO RIO GRANDE DO SUL, TECNOLOGIA DA MADEIRA, 2., 1992, Santa Maria. Anais... Esteio: UFSM/AGEFLOR/CEPEF/FATEC, 1992. p. 9-29.

KRETSCHMANN, D. E. Wood handbook: wood as an engineering material. Madison: USDA Forest Service, 2010. 62 $\mathrm{p}$.

LARSON, P. R.; KRETSCHMANN, D. E.; CLARK III, A.; ISEBRANDS, J. G. Formation and properties of juvenile wood in southern pines: a synopsis. Madison: USDA Forest Service, 2001. 42 p. (General Technology Report FPLGTR, 129).

MILLETT, M. A. Chemical brown stain in sugar pine. Journal of Forest Products Research Society, Madison, v. 2, n. 5, p. 232-236, 1952.

SANTINI, E. J. Qualidade de madeira seca. In: SEMINÁRIO SOBRE SECAGEM DE MADERA, 1., 1992, Santa Maria. Anais... Santa Maria: UFSM/CEPEF/FATEC, 1992. p. 6073.

SCHNEIDER, P. R.; FINGER, C. A. G.; HOPPE, J. M. Efeito da intensidade de desrama na produção de Pinus elliottii Engelm. implantados em solo pobre no Estado do Rio Grande do Sul. Ciência Florestal, Santa Maria, v. 9, n. 1, p. 35-46, 1999.

VEIGA, A. A. Glossário em dasonomia. São Paulo: Secretaria de Agricultura e Abastecimento, 1983. 118 p. (Publicação IF, 4). 